\title{
IMAGENS DA AMAZÔNIA: OLHARES INTERCULTURAIS
}

\author{
Benedita Afonso Martins*
}

RESUMO:

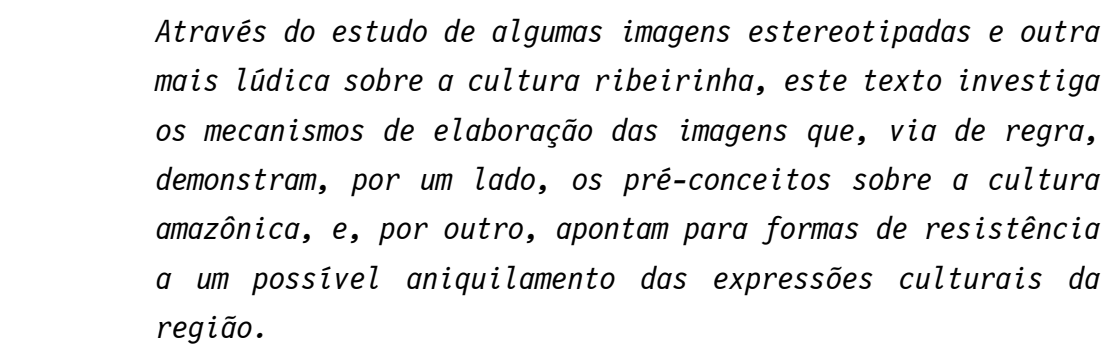

PALAVRAS-CHAVE: imagens, estereótipos, cultura ribeirinha, resistência.

Há séculos, desde 1541-2, época das primeiras expedições em busca do Eldorado, a Amazônia tem sido enfocada sob dois pontos extremos: ora como o inferno verde, ora como o paraíso. As imagens elaboradas pelo estrangeiro sobre o espaço e a cultura amazônica portam o tom do exagero. Não há como negar que a imensidão de espaços inabitados espanta e impressiona a quem chega. A surpresa ante ao desconhecido é natural, o encantamento e o deslumbre são sensações que acompanham o visitante de qualquer cidade, seja ela um centro considerado patrimônio histórico ou um espaço ecológico, considerado "celeiro do mundo".

Mas são provocações diferentes que incitam o forasteiro. Numa cidade histórica o encantamento é de outra natureza. 0 deslumbre decorre da grandeza dos feitos arquitetônico-artísticos, da sinuosidade das formas, da conservação do legado e da garantia da sua permanência enquanto peçasmonumentos construídos pelo e para o homem. Nessa cidade, as grandezas estão tombadas, resguardadas para as gerações vindouras.

* Doutora em Letras: Literatura, História e Memória Cultural (Área de concentração: Literatura Comparada), 2004. 


\section{EMTESE}

Belo Horizonte, v. 9, p. I-28I, dez. 2005

$\mathrm{Na}$ Amazônia, apesar das devastações constantes, ainda existem muitos espaços inexplorados e até dá para concordar com Euclides da Cunha. Ele afirmou que a imensidão da natureza amazônica não estava arrumada, quando o homem nela se estabeleceu e começou a alterar a paisagem. Na Amazônia, as abundâncias da biodiversidade e da riqueza cultural, não estão conservadas entre as paredes protetoras de um palácio planejado. A tendência às descrições exageradas torna-se inevitável para a maioria dos forasteiros ao se depararem com um espaço imensurável e, à primeira vista, indecifrável.

Desde os primeiros relatos dos viajantes-navegadores pelas águas amazônicas é que a região foi transformada em objeto do desejo e da cobiça de olhos provindos de todos os lugares. Os estudiosos, aventureiros ou entediados senhores de posse, para cá se deslocavam em buscas diversas, desde os recursos naturais à promessa do encontro daquele espaço paradisíaco perdido há muito tempo, em sua terra natal. Os forasteiros partiam em busca do que imaginavam encontrar, alimentados que foram pelas expectativas despertadas pelos relatos lidos e pelas notícias que recebiam sobre o que os seus predecessores haviam registrado, como imagem dos habitantes do local.

Assim, as imagens foram construídas nos moldes fixados pelo olhar estrangeiro, o olhar do estereótipo que fixa e congela as imagens-conceitos, por eles elaborados. Ao invés de focarem as imagens em movimentos constantes, conforme requer a dinâmica dos contatos e das trocas interculturais, eles as fixaram sob um único foco. As narrativas registradas à época portavam os ideais da expansão colonialista imbuídas das idéias do progresso e da civilização, que deveriam estender os beneficios do desenvolvimento a todos os povos encontrados em condições nada compatíveis com as idéias de crescimento sócioeconômico-culturais dos estrangeiros. Estes ansiavam prestar serviços de saneamento, crença, leis e bons modos aos povos nativos, considerados incultos e selvagens.

Um exemplo de metáfora que foi tomada como conceito teóricoexplicativo da complexidade da selva, foi o de que a Amazônia seria um inferno verde. Essa frase foi formulada, durante delírio febril do personagem do romance Inferno verde de Alberto Rangel (Rangel, 1927), cujo tema é uma das questões recorrentes na era da borracha: as condições precárias da vida dos trabalhadores nos seringais. 0 autor francês retrata, ainda, mais duas imagens 
grotescas no romance, a da cabocla Maibi, que teve seu corpo cravejado em uma seringueira, com tigelas presas em partes do corpo para aparar o seu sangue. A mulher coisificada, durante um descontrole do marido, teve sua vida ceifada a escorrer em forma de sangue-leite-látex, numa simbiose com a árvore provedora, à beira da extinção.

A outra imagem é a do homem sujeitado que, em defesa do seu pedaço de chão, se enterra sob a árvore apuizeiro, num gesto desesperado de reação contra os desmandos dos senhores de posse. As imagens tomadas como metáforas da condição social do seringueiro, causam impacto por representarem situações angustiosas vivenciadas pelos garimpeiros. Alberto Rangel, ao contrário do escritor português Ferreira de Castro, autor do livro $A$ selva, não vivenciou o drama dos seringueiros, mas a crueza da selva está presente na linguagem densa que o autor utiliza nas falas dos personagens e nas formas dramáticas com que eles se entregam às intempéries da desorganização social e das péssimas condições de trabalho, impostas pelos donos dos seringais.

Essas imagens da exploração de um povo desamparado pairam no imaginário dos outros povos como retratos definidores da cultura ribeirinha. Dessa forma, via produções discursivas sobre as primeiras impressões de determinados aspectos geográfico-culturais encontrados, as imagens sobre a região se propagaram e sobrevivem, soberbas, no imaginário, tanto do povo ribeirinho quanto em grande parte das produções literárias sobre a cultura amazônica. As imagens foram tomadas não apenas como objeto de análise, mas também como parte da reflexão sobre a elaboração dos estereótipos.

$\mathrm{Na}$ trama de Alberto Rangel, o homem ainda não toma o lugar do personagem central. Ele é vítima da ordem natural, simples representante das condições adversas da vida na selva. É a selva a protagonista a impor ou a conduzir os destinos dos que nela estão. A reunião do exotismo e do humano, do triunfo grandioso da natureza e da resistência dos que nela habitam despertam a atenção para outro aspecto da Amazônia, o da experiência humana em tela, até então desconsiderada pelos relatores da vida na hiléia. Mas, ainda nessa obra, o humano está submetido às intempéries e caprichos da natureza, e veicula as dicotomias: natureza-cultura, civilizado-primitivo, algoz-vitima. 0 autor reitera as representações de segunda mão, por assim dizer, na medida em que os referenciais do personagem principal do romance são registros do imaginário predominante à época. 


\section{EM TESE}

Belo Horizonte, v. 9, p. I-28I, dez. 2005

A ficção enfatiza, ao invés de desmistificar, as atrocidades descritas em documentos divulgados sobre a selva amazônica, durante o curto período do ciclo da borracha, época que mais atraiu aventureiros e trabalhadores esperançosos de uma vida melhor, em função do ouro negro que encontrariam em abundância nas seringueiras. Dada a condição de prisioneiros da selva, um dos lemas dos seringueiros era: "Tirar saldo", uma obsessão do trabalhador do seringal que via na quitação do débito, contraído junto ao patrão, a única chance de recuperar a liberdade, naquele regime da indústria seringueira estabelecido de forma abominável: a escravatura branca. A esperança de libertar-se das dívidas era outra ilusão, o débito aumentava proporcionalmente aos sacrifícios dos condenados nas verdes matas.

Para desfocar um pouco desse quadro embaçado pelas tintas do exagero, ou de uma propalada originalidade das expressões culturais amazônicas, tomo algumas narrativas orais populares da região. 0 objetivo é contrapor as idéias das imagens estereotipadas sobre a cultura amazônica ou amenizar o horror provocado pelas imagens grotescas registradas no livro do escritor Alberto Rangel.

Das narrativas orais populares retiro um "conceito", extraído de um dito popular: "Foi boto sinhá", inserido em letra de música composta por Waldemar Henrique e Antônio Tavernard. A frase foi tomada, senão como conceito teórico, como forma de explicar as transgressões cometidas pelas moças de família que, de repente, apareciam grávidas. A explicação para o pai desconhecido: "- é filho do boto". 0 mito do Boto como expressão lúdica de uma das formas de resistência do imaginário caboclo amazônida. Esse mito representa uma carga de subjetividade reprimida, em função talvez, do complexo de colonizado que ronda os povos da região.

0 Boto é um dos mitos mais recorrentes no imaginário do povo amazônida, e a ele é atribuída a responsabilidade de ora ser a causa da perdição das mulheres, ora de ter o mérito de salvá-las de uma punição severa ou da discriminação por praticarem atos libidinosos, sem o consórcio de uma união abençoada por Deus. 0 paradoxo perdição/salvamento atribuído à selva amazônica penetrou no imaginário local, de tal forma, que até as lendas e mitos típicos da região apresentam tais extremos.

As narrativas do Boto, selecionadas neste ensaio, possibilitarão uma leitura menos densa do que a leitura das imagens que retratam a vida 
errante e cruel dos trabalhadores dos seringais. As narrativas ilustram as inúmeras possibilidades de enunciação de uma mesma história, ao sabor da imaginação de cada narrador, numa demonstração de que até os mitos, apesar de manterem aquele algo invariável que os caracteriza, permitem ou sugerem outros arranjos. E, para além da ficção e das alterações que os atualizam, os novos contadores enriquecem e garantem a sobrevivência dos mitos. Estes serão sempre identificados pelos ouvintes/leitores/narradores que os conhecem, independente do novo tom acrescentado no ato da performance.

Os mitos atuam no imaginário individual ou coletivo como uma espécie de eco de vozes longínquas a entoar uma música que remonta a tempos idos, a memórias indeléveis que ressoam no inconsciente de cada indivíduo ou de cada comunidade. Essa é uma das razões por que todos os povos têm sua mitologia, cujas forças se impõem ou se gravam na memória individual ou coletiva. As versões do mito do conquistador-caboclo foram enfocadas enquanto forças dinâmicas e transgressoras utilizadas pelo povo ribeirinho, mesmo que de forma inconsciente, para burlar normas de uma moral rígida e machista.

Os mais antigos moradores da Amazônia contam que as índias, insatisfeitas com os maridos queixosos do sabor da comida preparada por elas, fugiam para o rio em busca de um grande peixe, a ele se entregavam e a satisfação sexual era maior do que a proporcionada pelos maridos. Essa lenda daria início, quem sabe, às inúmeras versões do peixe-homem-garanhão das águas amazônicas, cúmplice das artimanhas compensadoras dos caprichos ou das necessidades de mulheres nada passivas, frente aos desmandos dos seus maridos e aos costumes da época.

As versões do Boto, em tela, servem para enfocar algumas formas de transgressão, resistência e versatilidade do modo de ser do homem amazônico, que é muito mais versátil e rico do que os modelos para ele estabelecidos há muito. Ele, metamorfoseado, sempre, em homem branco, alto e bonito. Às suas artimanhas de sedução mulher nenhuma resiste. Essas versões apresentam ou acrescentam características inusitadas para o sedutor. Há Botos seduzindo homens também, numa demonstração da capacidade que o povo tem de enriquecer, preservar, resistir e atualizar o imaginário, responsável que é pela sobrevivência e o repasse das mais antigas narrativas às novas gerações. 


\section{EMTESE}

Belo Horizonte, v. 9, p. I-28I, dez. 2005

Essa é mais uma ilustração de que os mitos servem para registrar um fato realmente ocorrido, passar uma mensagem, imbuir o povo de valores "universais", explicar a causa de "fenômenos" desconhecidos ou compreender os temas universais: origem do universo, origem do ser humano, vida e morte, noção do bem e do mal. 0 mito é um dos elementos fundamentais que compõem a cultura de cada povo. E, como tal, evolui conforme as transformações culturais da comunidade a qual "pertence". Ele contém uma gama de conhecimentos roubados e trocados entre os povos.

As narrativas do mito tomadas como elaboração discursiva, entrecruzadas com elementos sócio-histórico-culturais do povo ribeirinho e construídas, como toda produção literária, num determinado contexto. No caso do Boto, o mito justificaria, em parte, os atos condenáveis praticados pelas mulheres burladoras de preceitos morais. 0 mito enquanto uma narrativa, sob o signo da transgressão. Sem a preocupação de identificar ou de explicar o seu surgimento, as primeiras referências ao Boto, foram registradas a partir do século XIX. Desde então, o "Dom Juan da Amazônia" vem encantando mulheres e homens. Assim é conhecido o Boto Cor-de-rosa, ser fantástico que habita os rios da Amazônia.

Segundo o poeta paraense, João de Jesus Paes Loureiro, a teogonia cotidiana construída no mundo amazônico, revela uma espécie de harmonia cósmica. Aqui o homem estabelece, via recursos estéticos, a conversão da realidade em signos e, para esse autor, a natureza não mais se comporta como a vingadora implacável das atividades do homem. Ao contrário, é "através de labores do dia-a-dia, do diálogo com as marés, do companheirismo com as estrelas, da solidariedade dos ventos que impulsionam as velas, da paciente amizade dos rios" (Loureiro, 1995: 63) que o homem se integra à natureza, se emaranha nas ramas locais, se alimenta do gosto selvagem dos frutos, se inunda de água por todas as veias, se fortalece com a proteção das divindades elementares. É da natureza que o ribeirinho retira o seu jeito de viver.

Desde os primeiros tempos, os mitos surgem aliados a outras formas de discurso, para explicar o não compreendido ou o não aceito, e para ajudar o homem a entender tudo aquilo que ultrapassa a mera intelecção. A recorrência aos mitos é uma forma de buscar a justificativa, a causa primeira do ocorrido, é ainda uma tentativa do homem de organizar o que o cerca, o que 0 atormenta. 
É uma estratégia para conviver com e aceitar os seus medos, seus desejos e necessidades ou mesmo uma forma de mascarar a sua situação de desamparo enquanto ser definido na e pela linguagem. Mas o mito, enquanto forma narrativa construída na e pela linguagem, não só explica como desestrutura o estabelecido. Há uma ambivalência inerente à noção ou às funções do mito: apaziguam por um lado, violentam e desestruturam, por outro.

No surgimento do mito do Boto, a sua função não seria diferente. Nos casos de violação da moral, ele ajuda o homem a perdoar e relevar uma das atitudes mais temidas, a de ser traído. A traição praticada, fruto de algo não entendido, é aceita naturalmente. Assim, até mesmo atos reprovados, como o adultério, podem ser esquecidos, já que o responsável pelo pecado teria sido alguém "sobrenatural", ou de natureza estranha e incontrolável pelo homem comum.

Mas o Boto, o D. Juan Amazônico, às vezes se deixa morrer, quando apanhado pelos furiosos homens traídos, sob o impulso da primeira reação. Ele também é visto como o sugador de energia das mulheres que, durante o intercurso do enlevo, desfalecem de tanto prazer, causado talvez, pelo desconhecimento da força das pulsões sexuais latentes, e nem sempre admitidas, nas mulheres, principalmente à época em que imperavam os valores machistas.

0 mito que mata, que se deixa morrer e que salva. Um ser híbrido mistura ou fusão de peixe-homem, homem-peixe. Ele, em suas aparições, toma, repentinamente, a forma humana. Esse é um dos motivos de haver as mais variadas versões, para dar conta do seu surgimento. 0 mito do boto é odiado por um lado, temido e respeitado por outro. Ele não é um homem qualquer, a quem se possa condenar a uma pena estabelecida pela justiça terrestre. Ele só aparece para divertir, entreter, enredar e proporcionar prazer às insatisfeitas mulheres de determinados ribeirinhos. Não se ouvem as mesmas aventuras do Boto na zona urbana de Belém. Ele é tipicamente um ser das margens ribeirinhas.

0 Boto é 0 encantador das mulheres, transformado em belo rapaz, sempre vestido de terno e chapéu, para esconder o furo no alto da cabeça, por onde respira. Esta é a marca que denuncia a sua condição de ser híbrido. Ele percorre as vilas e povoados às margens dos rios, penetra nas festas para as quais não foi convidado. No momento em que entra no salão, todos os olhares dos presentes se voltam para a figura encantadora que envolve a todas as mulheres que desejar e, quase sempre, as abandona com um filho no ventre. Há 


\section{EM TESE}

Belo Horizonte, v. 9, p. I-28I, dez. 2005

até versões de moças fecundadas durante o sono. A narrativa abaixo é um exemplo das inúmeras versões do Boto. Esta contém, senão todos, a maioria dos elementos que compõem o imaginário dos ribeirinhos sobre os poderes do príncipe das caboclas ribeirinhas.

\section{Célia e o boto cor-de-rosa}

... Jacques Cousteau tinha razão: ele existe!

Eu estive numa casa, numa casa chamada... num lugar chamado Anapu.

Eu moro... parei uns quatro meses naquele rio. Então, teve uma moça lá, que, conversando comigo, ela me disse:

- Você sabia, que teve uma prima minha que casou com o boto?

Aí, eu disse:

- Como?

Ela disse:

- Porque de noite, sabe, a gente ia... meu tio apagava a luz... Ela contando... Aí, então, chegava um rapaz muito bonito. Loiro, de olho azul, né. E essa moça estava às vezes dormindo. E esse rapaz chegava, chamava ela. Ela levantava e, por fim, ele levou uma vez. Da outra, ela não voltou mais.

Aí, a mãe chamou o pai dela e foram e deram o alarme. E a menina tinha ido embora pro rio. Aí, ficaram naquele negócio: será que o boto carregou? ou ficou? Ou cobra? Alguma coisa.

- Passados os dias, - diz a moça pra mim - diz que passados os dias a moça apareceu.

Eu disse:

- Como você viu?

Ela disse:

- Porque eu estive no fundo com o meu namorado. Ele é muito bonito.

(...)

Aí, a mãe dela e mais um irmão que ela tem, que eu conheci, também, lá, no rio Anapu, botaram ela no barco chamado.... chamava-se Santa Terezinha. E, esse barco fazia linha Belém-Igarapé Mirim, lá. E ela foi pra esse lugar, pra Belém. Quando chegou de meia viagem... ela contou que o boto ia seguindo ela, mesmo assim... Ela não parava na rede.

(...)

- Não, pode deixar. Ela vai aparecer.

(...)

- Lembro. 0 nome dela chama-se Célia. Ela era morena, cabelo meio pixaim.

E ela era moça tão bo... bonita demais, sabe? Era muito bonita.

Uma das filhas que eu conheci, era a mais bonita que tinha das outras. Então, as irmãs dela, quando tinha festa na casa, assim... quando tinha festa, que o pai dela fazia o salão, ele vinha dançar com ela. Mas era um dos rapazes mais cobiçados, ali no rio. Era esse dito rapaz que chegava. E os próprios rapazes que chegavam diziam assim.

- "0lha, chegou o Príncipe".

Chamavam pra ele de Príncipe.

E, aí, foram descobrir que era 0 boto. 0 boto cor-de-rosa, esse que é do Amazonas. (Informante: Maria José de 01 iveira da unha). (Simões \& Golder, 1995: 99-101). 
Nessa versão, o Boto é descrito como o príncipe encantado que alimenta 0 imaginário das mocinhas sonhadoras, um típico descendente da raça européia, loiro, alto, de olhos azuis. É estranho que para tal beleza até os homens se rendem. Estes por acreditarem no mistério da aparição e da transformação do peixe em homem. As mulheres por encontrarem a beleza masculina e perfeita desenhada nos contos de fadas que ouviram ou que leram. Ao se depararem com tamanho esplendor, elas não têm tempo nem disposição para racionalizar, apenas entregamse aos mais recônditos anseios. Há, nessa versão, outro elemento comum à maioria delas, a família da seduzida aceita o fato com uma certa naturalidade. Foi 0 Boto. E com ele ninguém pode. 0 jeito é aceitar que perderam a filha para forças outras, cujo entendimento ultrapassa qualquer forma de resistência.

\section{0 boto e o rapaz}

Aquele boto era uma bota?

Ela ia lá pro barco, né? 0 barco deles vivia lá no laguinho. E quando era de noite, ia pra lá. 0 pai dele mandava ele dormir lá a bordo, pra vigiar o motor. Quando era ali umas nove horas da noite, que ele estava deitado, ele via... Ela chegava. Chegava aquela moça, subia na beira do motor, tirava a roupa, pegava no punho da rede dele e sacudia até ele acordar. Quando ele acordava, ela já estava lá em pé, olhando pra ele. Aí, ela deitava com ele na rede e passava a noite com ele.

Eu dizia:

- Aí, tu não tinhas medo, Davi?

- Eu não, ele dizia.

Coitado... era o boto que dormia com ele.

(Pesquisadora: Edilene Pena Ferreira; Informantes: Maria José 0liveira da Cunha). (Simões \& Golder, 1995: 19).

Mais uma versão do Boto para demonstrar que o herói mítico desenvolve a capacidade de metamorfosear-se para enganar a presa. Este é mais um dos elementos comuns às narrativas. 0 fato de ser enganado por um ser mítico seria outra forma a que o próprio homem recorre para camuflar os seus desejos e atos transgressores. 0 caboclo, ao ser flagrado mantendo relações sexuais com 0 peixe-boto, desculpa-se afirmando que fora enfeitiçado, que agira sob efeito de uma espécie de vertigem. Na versão acima, o rapaz prefere acreditar e ver uma moça ao seu lado, com quem passava as noites. Embora ninguém 1he desse crédito: "Coitado... era o boto que dormia com ele".

Das garras do Boto ninguém escapa. Assim, o representante dos machos sedutores finda por "desmoralizar" os parceiros de conquistas amorosas, e as histórias de botos gays são aceitas da mesma forma que as tradicionais. 


\section{EM TESE}

Belo Horizonte, v. 9, p. I-28I, dez. 2005

No mundo do imaginário não haveria senões, tudo poderia acontecer. Nesse mundo, princípios morais que tolhem a todos não teriam alcance. Mas vale lembrar que da construção do imaginário fazem parte o logro, o engano, os subterfúgios e as armadilhas que o próprio ser "inventa" para aceitar tudo aquilo que a razão não esclarece. 0 imaginário é também o espaço idealizado, - lócus do sonho e da utopia.

Os mitos representam, ainda, a história atemporal, aquela que se repete e permanece enquanto representação ativa da identidade cultural de uma comunidade, permeados ou amparados pela sabedoria, experiência e pelo processo de atualização inerentes ao ato de contar histórias. Cada narrador conta histórias a seu modo, a margem de variação é imensa, conforme a capacidade e a imaginação de cada pessoa. 0 processo do repasse das histórias não se completa, do oral ao escrito, à interação ao vivo ou mediada pelos recursos eletrônicos, de volta ao oral. A incompletude se evidencia a cada performance, a cada interação. 0 jogo do viver, narrar, representar, interagir é partida interminável a desafiar novos integrantes para outros repasses.

\section{ABSTRACT :}

Through the research about some stereotyped images and others more theatrical about riverine culture, this text investigates the methods of elaboration of the images which ones always show, to the other hand, the prejudices about Amazon Culture, and demonstrate forms of resistance against a future annihilation of the cultural expressions of the region, however.

KEY WORDS: images, stereotyped, riverine culture, resistance.

REFERÊNCIAS BIBLIOGRÁFICAS

LOUREIRO, João de Jesus Paes. Cultura amazônica. Uma poética do imaginário. Belém: CEJUP, 1995.

MARTINS, Benedita Afonso. Imagens da Amazônia: olhares interculturais. 2004. 244 p. Tese (Doutorado em Letras) Faculdade de Letras, Belo Horizonte.

RANGEL, Alberto. Inferno verde. Scenas e scenarios do Amazonas. Tours: Typographia Arrault \& Cis., 1927.

SIMÕES, Maria do Socorro; GOLDER, Cristopher (Org.) Santarém conta. Belém: CEJUP, 1995. 